\title{
A Rare Case of Peanut Allergy Manifesting as Benign Migratory Glossitis
}

\author{
Cathy Nikdel$^{1 *}$, Ana Ibarra Noriega ${ }^{2}$, Sayali Tungare ${ }^{2}$, Kian Nikdel1 \\ and Cleverick D Johnson ${ }^{1}$ \\ ${ }^{1}$ Department of General Practice and Dental Public Health, The University of Texas \\ Health Science Center at Houston School of Dentistry, USA \\ ${ }^{2}$ Department of Diagnostic and Biomedical Sciences, The University of Texas Health \\ Science Center at Houston School of Dentistry, USA
}

\section{Case Report}

Volume 3 Issue 4

Received Date: November 23, 2018

Published Date: December 18, 2018

DOI: $10.23880 /$ oajds-16000209

*Corresponding author: Cathy Nikdel, Department of General Practice and Dental Public Health, The University of Texas Health Science Center at Houston School of Dentistry, 7500 Cambridge Street, Suite 5417, Houston, USA, TX 77054, Tel: 713- 486 4277; Email: Cathy.K.Nikdel@uth.tmc.edu

\section{Abstract}

Prevalence of food allergies is increasing at a global level. Peanut allergy, specifically, is one that is becoming one of the most common food allergies. With various clinical and oral reactions, it is becoming a significant growing public health concern amongst infants, children, adolescents and adults. This article presents a case-report describing the characteristics of a patient's oral symptoms that consisted of oral lesions similar to those of a Geographic tongue in combination with a burning sensation. Geographic tongue is often associated with much oral pathology. Therefore, these symptoms may cause a confusion and a diagnostic challenge for the dental professional, leading to a misdiagnosis in patients with a peanut allergy. Individuals with peanut allergy may also have cross-reactivity with some legumes and tree nuts. As some dental materials contain these allergens, it is imperative for dental professionals to have awareness of those products and understanding of how to protect those patients in a dental environment.

Keywords: Peanut allergy; Oral pathologies; Migratory Glossitis or Geographic tongue

\section{Introduction}

Food allergies have become a public health challenge and is an issue of significance due to its growing prevalence over the past twenty years [1,2]. Prevalence of food allergies is not exclusive of children and has increased in the adult population: more than $45 \%$ of American adults with food allergies in 2016 had an adult onset [3]. Moreover, literature shows that food allergy prevalence is higher among adults and Asians, and women $[4,5]$. The prevalence of food allergies has mostly been measured from either self-reporting or parentreporting of allergy, and have been reported to have doubled in the past ten years in United Kingdom, North America and Australia.in the United States is estimated to affect $10 \%$ of the population [6,7]. 


\section{Open Access Journal of Dental Sciences}

The eight most common food allergens responsible for $90 \%$ of all allergic reactions are milk, eggs, peanuts, soy, wheat, tree nuts, fish and shellfish such as shrimp [6], however, a study on the self-reported National Health and Nutrition Examination Survey (NHANES), found the top three leading allergens to be milk, peanut and shellfish in both adults and children (Table 1) [5].

\begin{tabular}{|c|c|c|}
\hline \multirow{2}{*}{$\begin{array}{l}\text { Type of food } \\
\text { allergy }\end{array}$} & Children & Adults \\
\hline & $\%(95 \% \mathrm{CI})$ & $\%(95 \% \mathrm{CI})$ \\
\hline All foods & $6.53(5.69-7.37)$ & $9.72(8.94-10.5)$ \\
\hline Milk & $1.94(1.43-2.44)$ & $2.64(2.15-3.13)$ \\
\hline Shellfish & $0.87(0.56-1.17)$ & $2.04(1.70-2.38)$ \\
\hline Peanuts & $1.16(0.83-1.49)$ & $0.89(0.61-1.17)$ \\
\hline
\end{tabular}

Table 1: Three leading allergens according to NHANES data on self-reported prevalence of food allergies in the United States [5].

A reaction is usually triggered in those predisposed, when they either consume food containing an allergen or when they come in contact with, or inhale, an allergen [810]. The severity of reactions can range from an uncomfortable mild sneeze [9] to a life-threatening anaphylactic shock [11].

Many food allergies with an onset in infancy are outgrown in the later stages of childhood. Examples are milk and egg allergy, however, peanut and tree nut allergies are more persistent and can follow a person into teenage years or even originate and thrive in adulthood $[3,4,12]$.

Almost half $(40 \%)$ of adult Americans consume nuts on a daily basis either as a snack or as an ingredient in different types of food [13]. In fact, peanut consumption is so high that the US Census data reports that the peanut industry generates more than $\$ 14$ billion dollars by making peanut butter and roasting peanuts [14]. Although peanuts are thought by most to be part of the broad category of edible nuts, they do actually belong to the legume family such as lentils and beans. They grow underground and staying true to the legume family, have an edible seed that grows inside a pod, however, peanuts have a similar protein structure to those in tree nuts (such as almonds, Brazil nuts, walnuts, hazelnuts, macadamia nuts, pistachios, pecans, and cashews) [15].

Peanut allergy, with prevalence between $1.2 \%$ and $5 \%$ depending on the region, is one of the most common food allergies in the United States [12]. It affects both children and adults, with symptoms presenting as early as eleven months of age $[12,16,17]$.

Peanut allergy manifests clinically most commonly as eczema, rhinitis, laryngospasm, induced enterocolitis syndrome, diarrhea, and anaphylaxis [17] and in the oral cavity most commonly as edema, erythema, formation of vesicles and ulcers, lichenoid reactions, and leukoplakia [18]. However, symptoms are not limited to those mentioned and this wide-spectrum display of clinical and oral manifestations generate a challenge for the diagnosis and management of Peanut allergy [19]. This paper reports a case of a symptomatic case of peanut allergy manifesting as Benign Migratory Glossitis or Geographic tongue with burning sensations in a 35 year old AfricanAmerican woman with no significant medical or dental history.

An IRB was not obtained as it is not required to do so for a single case report, however, as per HIPPA regulations, we have de-identified all patient information. Patient consent was gained verbally and documented in the patient notes.

\section{The Case}

A 35 year old African-American woman presented to our Urgent Care clinic with a complaint of a patchy tongue followed with burning sensation. Medical history revealed that she was suffering from walnut allergy since one year ago. The patient's family history was non-contributory and her dental history had no significant findings. The patient explained that recently whenever she eats peanuts, she develops a reaction on her tongue and followed with a burning sensation.

Upon intraoral examination, we found the body and the lateral border of her tongue to have erythematous lesions with absence of filiform papilla (Figures $1 \& 2$ ). As no other abnormalities were found in the oral cavity, a diagnosis of peanut allergy was determined, however, a differential diagnosis of Benign Migratory Glossitis or Geographic tongue was also considered and the patient was advised accordingly. She was told to refrain from any food product containing peanuts and to rinse with saline solution two times per day until the lesions have healed. She was also advised to see an allergist to either get a skin-prick test and/or blood tests to determine the presence of IgE antibodies (immunoglobulin E), an antibody that binds to allergens and prompts the release of chemicals that cause discomfort and symptoms. The patient was asked to return after ten days for follow-up visit. 
At the follow up visit, the lesions had healed and she was no longer in discomfort. She informed us that she had as well as refrained from food containing peanut also received a skin prick test. The test had been done on the right side of her back. Approximately one hour after the allergen had been placed on the scratch, a large raised and itchy bump was observed which confirmed an allergic reaction to peanuts through a skin-prick test. As the lesions had healed and the patient had reacted positive to peanut allergen during the skin prick test, we decided that our diagnosis would be allergic to peanut and ruled out a differential diagnosis of Benign Migratory Glossitis.

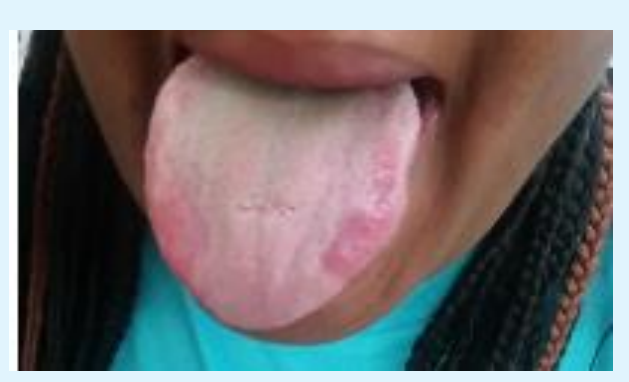

Figure 1: Erythematous lesions with absence of filiform papilla on the body and the lateral border of the tongue due to peanut allergy.

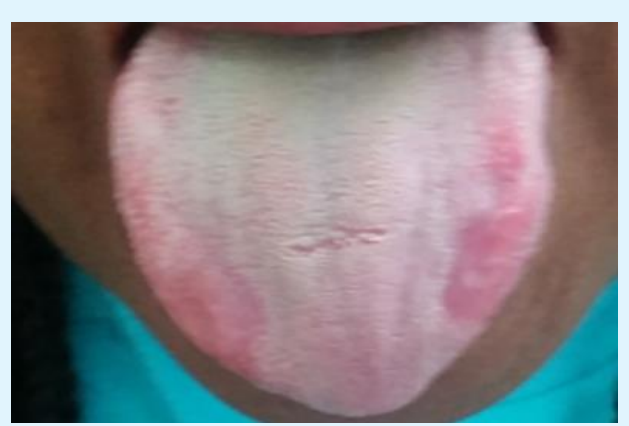

Figure 2: Lesions similar to those of Geographic tongue as a result of peanut allergy.

\section{Discussion}

This case of peanut allergy was rare due manifesting itself as lesions on the body and the lateral border of her tongue followed with a burning sensation and absence of filiform papilla. As common oral peanut allergy symptoms are edema, erythema, formation of vesicles and ulcers, lichenoid reactions, and leukoplakia [18], we were also leaning towards a differential diagnosis of Benign Migratory Glossitis or Geographic tongue.
Being allergic to peanuts, can be a debilitating condition. It compromises the life quality of those predisposed to it, as they have to at all times assess the food they eat, read the labels on food packaging or ask questions about how their food has been prepared. More than that, they have to also have great awareness of crosscontact, where the allergen has unintentionally come into contact with another food and their proteins mix, as the smallest amount of allergen could cause detrimental reactions in those with food allergy.

Therefore, the detection, diagnosis, and prevention of an individual's allergies are imperative to the well-being of our patients. A suspected food allergy either through medical history and/or manifestation of symptoms can be confirmed by a medical doctor or nurse through a skinprick test, where skin is exposed to the suspected allergen to be observed for signs of an allergic reaction. A skinprick test is usually safe for infants, children and adults and common test sites are skin on the patient's arms and the back [20]. However, sometimes it may be advised against if the patient has had a severe allergic reaction and an anaphylactic shock could be triggered, skin conditions such as severe eczema or psoriasis on testing sites where there is not enough clear skin for an effective test or possible drug interference with the allergen (Table 2). In those circumstances, a blood test is recommended for detection of food protein that start production of chemicals that cause symptoms [20].

\begin{tabular}{|c|c|}
\hline Medication group & Examples \\
\hline $\begin{array}{c}\text { Prescription } \\
\text { antihistamines }\end{array}$ & $\begin{array}{c}\text { Levocetirizine (Xyzal) and } \\
\text { Desloratadine (Clarinex) }\end{array}$ \\
\hline $\begin{array}{c}\text { Over-the-counter } \\
\text { antihistamines }\end{array}$ & $\begin{array}{c}\text { Loratadine (Claritin, Alavert), } \\
\text { Diphenhydramine (Benadryl, } \\
\text { others), Chlorpheniramine } \\
\text { (Chlor-Trimeton), cetirizine } \\
\text { (Zyrtec, others) and fexofenadine } \\
\text { (Allegra) }\end{array}$ \\
\hline $\begin{array}{c}\text { Tricyclic } \\
\text { antidepressants }\end{array}$ & $\begin{array}{c}\text { Nortriptyline (Pamelor), } \\
\text { Desipramine (Norpramin) }\end{array}$ \\
\hline $\begin{array}{c}\text { Heartburn } \\
\text { medications }\end{array}$ & $\begin{array}{c}\text { Cimetidine (Tagamet), Ranitidine } \\
\text { (Zantac) }\end{array}$ \\
\hline $\begin{array}{c}\text { Certain asthma } \\
\text { medication }\end{array}$ & $\begin{array}{c}\text { Omalizumab (Xolair). This } \\
\text { medications may interfere with } \\
\text { test results for six months or } \\
\text { longer even after usage. }\end{array}$ \\
\hline
\end{tabular}

Table 2: Examples of medications that may interfere with a skin-prick test.

Several studies document the sensitization to other legumes and nuts, and cross-reactivity in peanut-allergic 
individuals. Klemens, et al. performed a recent study where they concluded that $60 \%$ of patients being allergic to soy also were allergic to peanuts [21], and 20 and $40 \%$ of peanut-allergic individuals have a concomitant allergy to related tree nuts [21] (Figures 3 \& 4).

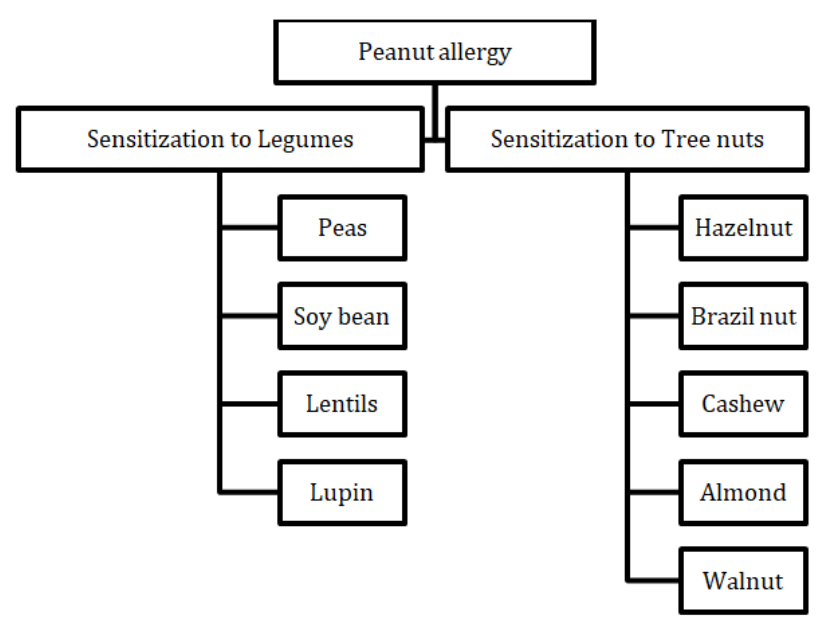

Figure 3: Cross-reactivity and sensitization to other legumes and tree nuts in peanut-allergic individuals.

With a changing global population health and a growing prevalence of food allergies over the past twenty years, dental professionals no longer only deal with allergies related to latex or penicillin. To avoid a possible risk of anaphylactic shock during patient care, it is imperative to take a thorough medical history to gain a better understanding of any previous allergies a patient may have experienced and their related symptoms.
Furthermore, many dental products commonly used in the dental office and sugar free gums contain food allergens such as peanuts, dairy, nut oils, eggs proteins or flavoring agents such as eugenol or preservatives. Having knowledge about them allows dental professionals to provide dental care under safer conditions for those patients who are predisposed to food allergens.

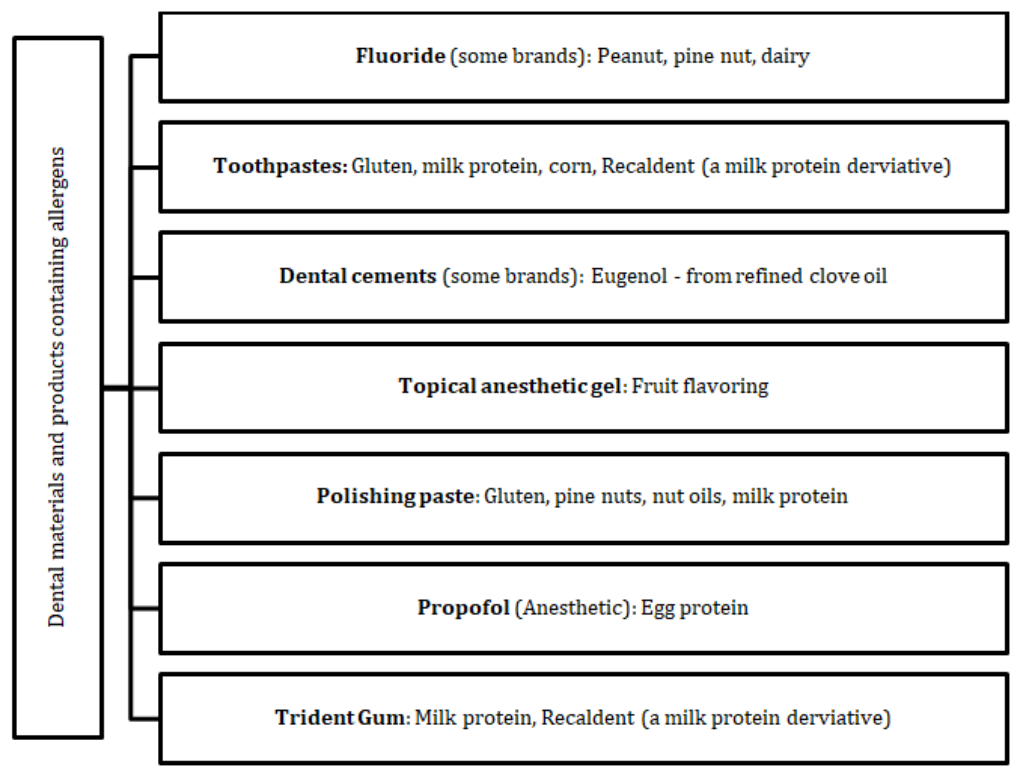

Figure 4: List of dental materials and products containing food allergens [22]. 


\section{Open Access Journal of Dental Sciences}

Other methods to further protect our patients at the dental the office from cross-contact with food allergens, are to restrict eating and drinking to designated areas such as a staff lounge or outside the dental office. Food and beverages should not be consumed in treatment rooms or instrument processing areas as per CDC guidelines [23].

\section{Conclusion}

Peanut allergy is one of the most common food allergies in both adults and children. With a rising number of patients having sensitivity to peanuts and products containing peanuts, most dental professionals worldwide will encounter patients with this debilitating condition. Individuals with this condition may also experience crossreactivity with common tree nuts and legumes. Therefore, awareness of detection, diagnosis, prevention of food allergies are imperative to the well-being of the dental patient population.

\section{References}

1. Verrill L, Bruns R, Luccioli S (2015) Prevalence of selfreported food allergy in U.S. adults: 2001, 2006, and 2010. Allergy and Asthma Proceedings 36(6): 458467.

2. Tang ML, Mullins RJ (2017) Food allergy: is prevalence increasing? Intern Med J 47(3): 256-261.

3. Gupta R, Blumenstock J, Warren C, Mittal K, Kotowska J, et al. (2017) OR077 The prevalence of nut and seafood allergies among adults in the United States. Annals of Allergy, Asthma \& Immunology 119(5): S11.

4. Acker WW, Plasek JM, Blumenthal KG, Lai KH, Topaz $M$, et al. (2017) Prevalence of food allergies and intolerances documented in electronic health records. J Allergy Clin Immunol 140(6): 1587-1591.

5. McGowan EC, Keet CA (2013) Prevalence of selfreported food allergy in the National Health and Nutrition Examination Survey (NHANES) 2007-2010. J Allergy Clin Immunol 132(5): 1216-1219.

6. Savage J, Johns CB (2015) Food allergy: epidemiology and natural history. Immunol Allergy Clin North Am 35(1): 45-59.

7. Sicherer SH, Sampson HA (2014) Food allergy: Epidemiology, pathogenesis, diagnosis, and treatment. J Allergy Clin Immunol 133(2): 291-307.
8. Kulis M, Wright BL, Jones SM, Burks AW (2015) Diagnosis, management, and investigational therapies for food allergies. Gastroenterology 148(6): 11321142.

9. Gelardi M, Ciprandi G, Incorvaia C, Buttafava S, Leo E, et al. (2015) Allergic rhinitis phenotypes based on mono-allergy or poly-allergy. Inflamm Res 64(6): 373-375.

10. Patel BY, Volcheck GW (2015) Food Allergy: Common Causes, Diagnosis, and Treatment. Mayo Clin Proc 90(10): 1411-1419.

11. Leatherman BD (2014) Anaphylaxis in the allergy practice. Int Forum Allergy Rhinol 4(Suppl 2): S60-65.

12. Kattan J (2016) The Prevalence and Natural History of Food Allergy. Curr Allergy Asthma Rep 16(7): 47.

13. King JC, Blumberg J, Ingwersen L, Jenab M, Tucker KL (2008) Tree nuts and peanuts as components of a healthy diet. J Nutr 138(9): 1736-1740.

14. Bureau UC (2018) Peanut Butter Lovers Month.

15. Lomas JM, Järvinen KM (2015) Managing nut-induced anaphylaxis: challenges and solutions. J Asthma Allergy 8: 115-123.

16. Grief SN (2016) Food Allergies. Prim Care 43(3): 375391.

17. Turnbull JL, Adams HN, Gorard DA (2015) Review article: the diagnosis and management of food allergy and food intolerances. Aliment Pharmacol Ther 41(1): 3-25.

18. Torgerson RR, Davis MD, Bruce AJ, Farmer SA, Rogers RS, et al. (2007) Contact allergy in oral disease. J Am Acad Dermatol 57(2): 315-321.

19. Minciullo PL, Paolino G, Vacca M, Gangemi S, Nettis E (2016) Unmet diagnostic needs in contact oral mucosal allergies. Clinical and Molecular Allergy: CMA 14(1): 10.

20. https://www.mayoclinic.org/testsprocedures/allergy-tests/about/pac-20392895.

21. Bublin M, Breiteneder H (2014) Cross-Reactivity of Peanut Allergens. Curr Allergy Asthma Rep 14(4): 426. 


\section{Open Access Journal of Dental Sciences}

22. http://drgaryglassman.com/wp_content/uploads/20 17/03/Beware-of-Food-Allergens-In-Dentalproducts\%C2\%BB-Lynchburg-Mama.pdf.
23. Kohn WG, Collins AS, Cleveland JL, Harte JA, Eklund $\mathrm{KJ}$, et al. (2003) Guidelines for infection control in dental health-care settings-2003. MMWR Recomm Rep 52(17): 1-61.

(c) (1) 